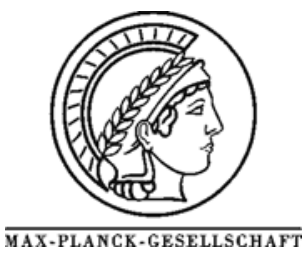

\title{
Oxidative dehydrogenation of propane over low-loaded vanadia catalysts: Impact of the support material on kinetics and selectivity
}

\author{
A. Dinse ${ }^{\mathrm{a}}$, B. Frank ${ }^{\mathrm{a}}$, C.Hess ${ }^{\mathrm{b}}$, D. Habel ${ }^{\mathrm{c}}$, R. Schomäcker ${ }^{\mathrm{a}}{ }^{*}$ \\ ${ }^{a}$ Department of Chemistry, Technical University of Berlin, Straße des 17. Juni 124, D-10623 Berlin, Germany \\ ${ }^{b}$ Department of Inorganic Chemistry, Fritz-Haber-Institute of the Max-Planck-Society, \\ Faradayweg 4-6, D-14195 Berlin, Germany \\ ${ }^{\mathrm{c}}$ Department of Materials Science and Technology, Technical University of Berlin, Englische Straße 20, \\ D-10587 Berlin, Germany
}

*Corresponding author: e-mail schomaecker@tu-berlin.de,

Received 26 January, 2008 Accepted 1 April 2008, Available online 12 April 2008.

\begin{abstract}
The influence of the support material of low loaded $\left(<2 \mathrm{~V} \mathrm{~nm}^{-2}\right)$ vanadia catalysts on selectivities, activation energies and turn over frequencies in the oxidative dehydrogenation of propane and the combustion of propene was investigated. $\mathrm{CeO}_{2}, \mathrm{TiO}_{2}, \mathrm{Al}_{2} \mathrm{O}_{3}, \mathrm{ZrO}_{2}$ and $\mathrm{SiO}_{2}$ supported catalysts were prepared by saturation wetness impregnation in toluene. Characterization with temperature programmed reduction and Raman spectroscopy revealed a high dispersion of surface vanadia species for all investigated catalysts. The impact of heat and mass transfer limitations on the catalytic performance has been thoroughly excluded. Selectivities towards propene as well as activation energies strongly depend on the support material. For all catalysts, propene selectivity increases with temperature. Deconvolution of the reaction network of ODP into decoupled reactions of different reactants for at least three of the catalysts is not possible, because of a significant impact of the oxidation state of the catalyst on the reaction. Except for the $\mathrm{CeO}_{2}$ supported catalyst, the contribution of the bare support material on the activity can be neglected.
\end{abstract}

Keywords: Oxidative dehydrogenation; Propane; Propene; Supported vanadia catalysts; Selectivity;

\section{Introduction}

The production of lower alkenes is of increasing interest, because they are important raw materials for the chemical industry. An attractive reaction is the catalytic formation of propene via oxidative dehydrogenation of propane (ODP). The energy demand of this reaction is much lower than for conventional catalytic cracking and dehydrogenation processes used predominantly today. The oxidative pathway is exothermic, thermodynamically not restricted, the reaction temperature is lower and coke deposition is minimized in the oxidizing atmosphere. A variety of differently supported vanadia catalysts have been investigated in oxidative dehydrogenation reactions [1-4]. Although supported vanadium oxides exhibit a higher selectivity towards the desired alkene than bulk $\mathrm{V}_{2} \mathrm{O}_{5}[5$, 6], their performance is still insufficient for industrial application. The selectivity is restricted by fast side and consecutive reactions. The $\mathrm{C}-\mathrm{H}$ bond activation, which is considered to be the rate determining step of the reaction [7], is kinetically less energy demanding for alkenes than for alkanes. The answer to this problem can be either the development of optimized catalysts or a novel process design, e.g., a minimization of the local oxygen concentration via reactant separation by oxygen ion conductive Perovskite membranes [8] or alternating feed of the reactor [9]. Intelligent catalyst design requires a profound knowledge of the reaction mechanism. However, a detailed understanding of the influence of the support material on the reaction mechanism of the ODP is still missing, despite 
numerous studies on the influence of support materials on the catalytic performance [10-12] as well as the kinetics of this reaction [4, 13-16]. A quantitative comparison of these results requires careful consideration of heat and mass transfer limitations. On the other hand, due to a lack in structural characterization of many catalysts used for kinetic studies, reproducibility of gathered data is not always granted. In the past only few studies were devoted to selectivity aspects of the ODP $[17,18]$, even though they state a powerful tool to ascertain models of possible reaction networks.

One of the objectives of catalysis research is to develop a detailed description of the relationship between structure and reactivity by bridging the gap between kinetic modeling, quantum chemical calculations and analytical characterization. From a structural point of view the surface of a support material allows for different arrangements of vanadium oxide species. For low surface vanadium densities $\left(<8 \mathrm{~V} \mathrm{~nm}^{-2}\right.$, silica: $\left.<2 \mathrm{~V} \mathrm{~nm}^{-2}\right)$ the presence of (i) monomeric species and (ii) dimeric/polymeric species has been suggested. At higher loadings also crystalline $\mathrm{V}_{2} \mathrm{O}_{5}$ (iii) is present $[19,20]$. It is still discussed in the literature, how to distinguish between (i) and (ii). However, species (iii) may be excluded with high certainty by analytical characterization using, e.g., Raman spectroscopy [21], which is of importance for quantification as enclosed vanadia species can not take part in the investigated reaction. Kinetic investigations reveal a low reaction order for oxygen and reaction orders in the range of one for propane [22, 23]. Previous studies [24, 25] underline the theory of a Mars-van-Krevelen mechanism as a microkinetic model, which suggests that lattice oxygen takes part in the reaction. Quantum chemical calculations by means of density functional theory (DFT) are currently exploring energetically favourable reaction sites in ODP. For silica supported vanadia catalysts calculations considered monomeric and dimeric vanadium oxide surface species to take part in ODP [26]. It is suggested that for a model (010) surface of $\mathrm{V}_{2} \mathrm{O}_{5}$ system at least two $\mathrm{V}=\mathrm{O}$ goups bonded by a $\mathrm{V}-\mathrm{O}-\mathrm{V}$ bond are required for the dissociative adsorption of propane [27].

Here we present data concerning kinetics and selectivities for the ODP over differently supported vanadia catalysts. Furthermore this study constitutes a basis for the detailed kinetic description of the introduced catalyst systems. The impact of mass- and heat transfer effects on the ODP even over a low $\left(<2 \mathrm{~V} \mathrm{~nm}^{-2}\right)$ loaded alumina supported catalyst has recently been reported [23]. The focus of this study are highly dispersed supported vanadia catalysts with the objective of a comparison of the gathered kinetic data with that originating from quantum chemical calculations [26] and other well characterized catalyst systems [28]. The disadvantage of catalysts providing a low surface density of vanadium is the possibility of propene adsorption on acidic sites of the bare support material, its consecutive decomposition and deep oxidation. On the other hand, these catalysts are considered to present a good starting point for a comparative study due to their high vanadium dispersion. The influence of pure support material was also taken into account in order to observe perturbing support influences besides acidic sites.

The general reaction network for ODP, which can be derived from the product distribution, is depicted in Fig 1. A parallel, as well as a consecutive reaction could be involved in the overall network. Propene is the primary product, whereas carbon oxides are generated via parallel combustion of propane or by secondary combustion of alkenes.

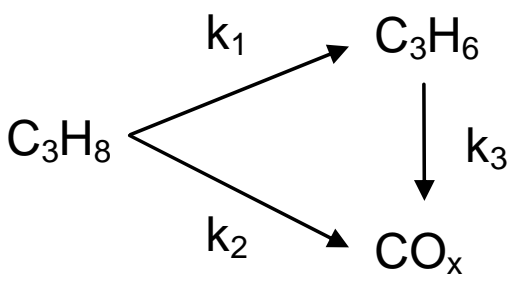

Fig. 1: Simplified reaction network of ODP

The oxidation of $\mathrm{CO}$ towards $\mathrm{CO}_{2}$ is rather slow and can usually be neglected.

\section{Experimental}

\section{1. Catalyst Preparation}

All catalysts were prepared by saturation wetness impregnation. The chosen support materials were alumina (Alfa Aesar), ceria (Alfa Aesar), titania (Sachtleben Chemie), zirconia (Alfa Aesar) and silica (BASF). Except for $\mathrm{CeO}_{2}$ these were received as porous pellets. Prior to the impregnation, pellets were crushed and sieved to a particle size fraction of 0.1 to $0.3 \mathrm{~mm}$. The $\mathrm{CeO}_{2}$ powder was first pressed to tablets at a pressure of 100 bar for $5 \mathrm{~min}$ and then crushed and sieved. The impregnation procedure consisted of the following steps:

First a saturated solution of vanadyl acetylacetonate (Sigma-Aldrich, $>97 \%$ ) in toluene was heated under reflux until the boiling point was reached. For each catalyst sample, about $2 \mathrm{~g}$ of the support was added to $250 \mathrm{ml}$ of the mixture and boiled under reflux for about $1 \mathrm{~h}$. The impregnated particles were thoroughly washed with fresh toluene to remove unbound vanadyl species, then dried at $353 \mathrm{~K}$ and finally, calcined in air at $773 \mathrm{~K}$ for $3 \mathrm{~h}$. The calcined catalysts were sieved again.

Please note that it was taken special care of preparing all catalysts the same way, using identical precursor concentrations, boiling and calcination times for each run. In the following impregnated and subsequently calcinated support materials are denoted as $\mathrm{V}-\mathrm{CeO}_{2}, \mathrm{~V}-\mathrm{TiO}_{2}, \mathrm{~V}$ $\mathrm{Al}_{2} \mathrm{O}_{3}, \mathrm{~V}-\mathrm{ZrO}_{2}$ as well as $\mathrm{V}-\mathrm{SiO}_{2}$ and pure support materials as $\mathrm{CeO}_{2}, \mathrm{TiO}_{2}, \mathrm{Al}_{2} \mathrm{O}_{3}, \mathrm{ZrO}_{2}$ and $\mathrm{SiO}_{2}$. 


\subsection{Physical Characterization}

Catalyst and support surface area was determined by nitrogen adsorption-desorption at liquid nitrogen temperature $(77 \mathrm{~K})$, using a Micromeritics 2375 BET device equipped with a Vacprep 061 degasser. Samples were degassed for $1 \mathrm{~h}$ at $300{ }^{\circ} \mathrm{C}$ and $0.15 \mathrm{mbar}$ before experiments to ensure a clean and dry surface. Surface areas were calculated using the method of Brunauer, Emmett and Teller (BET).

For the determination of the apparent vanadium oxide coverage, catalyst samples were given into a solution of nitric and hydrochloric acid. The concentration of vanadium was then determined by ICP with an ISA Jobin Yvon instrument.

\subsection{X-ray Diffraction Spectroscopy}

Experiments were carried out using a Theta-Thetadiffractometer D 5005 (Siemens) with $\mathrm{Cu}-\mathrm{K} \alpha$ radiation $(\lambda=$ $0,1542 \mathrm{~nm}$ ) at $40 \mathrm{kV}$ and $30 \mathrm{~mA}$ covering a scanning angle from 10 to $90^{\circ}$. Data analysis was done with Bruker Diffrac-Plus.

\subsection{Raman Spectroscopy}

Raman experiments were performed using a fiber probe, which was inserted into an in situ Raman cell. The powder samples were placed as is in a stainless steel sample holder with a $0.6 \mathrm{~mm}$ deep rectangular well covering an area of $(12 \times 8) \mathrm{mm}^{2}$. Prior to experiments the samples were dehydrated by treatment in $20 \% \mathrm{O}_{2} / \mathrm{He}\left(50 \mathrm{ml} \mathrm{min}^{-1}\right)$ at 300 ${ }^{\circ} \mathrm{C}$ for $60 \mathrm{~min}$ and subsequently cooled to room temperature. Raman spectra were recorded using $514 \mathrm{~nm}$ laser excitation $(5 \mathrm{~mW})$ at $5 \mathrm{~cm}^{-1}$ spectral resolution (Kaiser Optical). Sampling times were typically $30 \mathrm{~min}$. For the investigation of the catalysts structural stability, samples were also studied after the reaction. Prior to the Raman experiments these samples were treated in air at $450^{\circ} \mathrm{C}$ to reducce the absorbance of Raman light through carbon surface species. Some of the samples still had a greyish color after the treatment. However, to avoid structural changes of the catalyst the temperature was not further increased.

\subsection{Temperature-programmed reduction (TPR)}

For TPR experiments samples of ca. $200 \mathrm{mg}$ each were used. Experiments were run in a $5 \mathrm{Vol} \% \mathrm{H}_{2} / \mathrm{Ar}$ stream, with a heating rate of $20{ }^{\circ} \mathrm{C} \mathrm{min}^{-1}$ and $50 \mathrm{~cm}^{3} \mathrm{~min}^{-1}$ flow rate. Hydrogen consumption was recorded by an InProcessInstruments mass spectrometer. Ahead of experiments, samples were treated in an $\mathrm{O}_{2} / \mathrm{Ne}$ flow $(20 \mathrm{Vol} \%$ $\mathrm{O}_{2}$ ) at $773 \mathrm{~K}$ for $0.5 \mathrm{~h}$ and cooled down to $323 \mathrm{~K}$. Samples were then purged with $\mathrm{Ne}$ for $15 \mathrm{~min}$. The hydrogen flow was started subsequently.

\section{6- Catalytic measurements}

Experimental runs were carried out at temperatures between 673 and $773 \mathrm{~K}$ using u-shaped fixed bed quartz reactors at atmospheric pressure. For the measurements, catalyst amounts between $1-1000 \mathrm{mg}$ were portioned to 6 different channels. Using synthetic air as oxygen source, propane and oxygen were fed in the ratio $2: 1\left(\mathrm{C}_{3} \mathrm{H}_{8} / \mathrm{O}_{2} / \mathrm{N}_{2}\right.$ $=29.1 / 14.5 / 56.4)$ with a gas hourly space velocity (GHSV) of $6.610^{2}-6.610^{3} \mathrm{~h}^{-1}$. The experimental set-up including the product analysis is described in detail elsewhere [23]. The propane conversion was kept below $10 \%$, which enables for isothermal and differential conditions. To account for exclusion of mass transfer limitations, particle sizes of 100-600 $\mu \mathrm{m}$ where used, while for all other experiments catalyst particle sizes were $200-300 \mu \mathrm{m}$.

\subsection{Parameter determination}

Propane conversion $X$ and propene selectivity $S$ as functions of the respective concentration $c$ were calculated from Eqs. (1) and (2)

$$
\begin{aligned}
& X=1-\frac{c_{C 3 H 8}}{c_{C 3 H 8,0}} \\
& S=\frac{c_{C 3 H 6}}{c_{C 3 H 8,0}-c_{C 3 H 8}}
\end{aligned}
$$

Turn over frequencies were calculated from Eq. (3). It describes the number of converted moles of propane per vanadium atom and second:

$$
T O F=\frac{\dot{n}_{C_{3} H_{8}, 0} \cdot X_{C_{3} H_{8}} \cdot M_{V}}{m_{c a t} \cdot w_{v} \cdot 10^{-2}}
$$

where $\dot{n}$ is denoted as the flux, $X$ the conversion, $M_{\mathrm{V}}$ the molar mass of vanadium, $m_{\text {cat }}$ the catalyst weight and $w_{\mathrm{V}}$ the vanadium content by mass .

\section{Results}

BET surface areas for catalysts and support materials as well as apparent $\mathrm{VO}_{\mathrm{x}}$ surface densities and TPR peak maxima are shown in Tab. 1. Only a slight decrease in surface area after impregnation and calcination treatment is observed. 
Table 1: Surface areas, vanadia content and TPR peak maxima of differently supported catalysts

\begin{tabular}{llllll}
\hline & \multicolumn{2}{c}{ surface area } & \multicolumn{2}{c}{ loading } & TPR maxima \\
support & $\mathrm{m}^{2} / \mathrm{g}_{\text {cat }}$ & $\mathrm{m}^{2} / \mathrm{g}_{\text {support }}$ & $\mathrm{V} / \mathrm{nm}^{2}$ & $\mathrm{wt} \% \mathrm{~V}_{2} \mathrm{O}_{5}$ & ${ }^{\circ} \mathrm{C}$ \\
\hline $\mathrm{TiO}_{2}$ & 66 & 68 & 1,5 & 1,6 & 498 \\
$\mathbf{A l}_{2} \mathbf{O}_{3}$ & 96 & 100 & 1,4 & 2,1 & 515 \\
$\mathbf{Z r O}_{2}$ & 108 & 110 & 1,0 & 1,6 & 456 \\
$\mathbf{S i O}_{2}$ & 151 & 154 & 0,3 & 0,6 & 557 \\
$\mathbf{C e O}_{2}$ & 60 & 62 & 1,5 & 1,4 & 538 \\
\hline
\end{tabular}

Graph. 2 shows the results of TPR experiments. They show only one reduction peak for each catalyst, except for $\mathrm{V}-\mathrm{CeO}_{2}$, which shows a second weak peak at about $700{ }^{\circ} \mathrm{C}$. Please note, that there are no TPR signals for the bare support materials, except for $\mathrm{CeO}_{2}$ as discussed below.

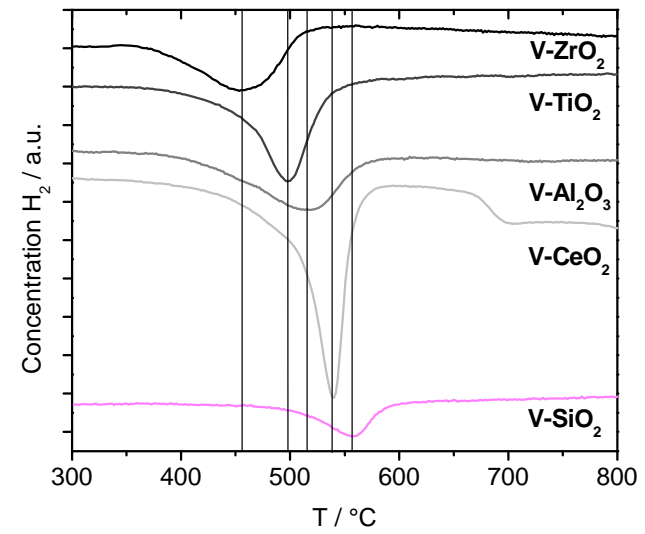

Fig. 2: TPR spectra of $\mathrm{V}-\mathrm{Al}_{2} \mathrm{O}_{3}, \mathrm{~V}-\mathrm{TiO}_{2}, \mathrm{~V}-\mathrm{CeO}_{2}, \mathrm{~V}-\mathrm{SiO}_{2}, \mathrm{~V}-\mathrm{ZrO}_{2}$. Lines to fix maxima of reduction peaks. Spectra are offset for clarity.

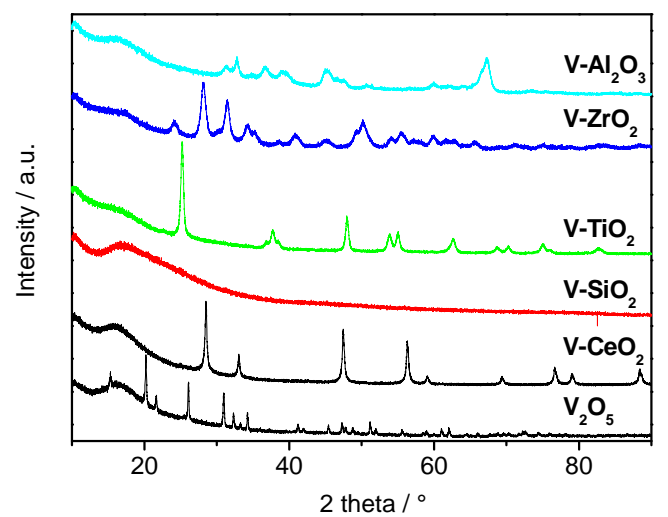

Fig. 3: $\mathrm{XRD}$ patterns of $\mathrm{V}-\mathrm{Al}_{2} \mathrm{O}_{3}, \mathrm{~V}-\mathrm{TiO}_{2}, \mathrm{~V}-\mathrm{CeO}_{2}, \mathrm{~V}-\mathrm{SiO}_{2}, \mathrm{~V}-$ $\mathrm{ZrO}_{2}$, and $\mathrm{V}_{2} \mathrm{O}_{5}$. The patterns are offset for clarity.
XRD patterns of the supported vanadium oxide catalysts are depicted in Graph. 3 together with the diffraction pattern of $\mathrm{V}_{2} \mathrm{O}_{5}$. The catalyst patterns are identical to those of the respective support material (only catalyst spectra shown here). The peak pattern of bulk $\mathrm{V}_{2} \mathrm{O}_{5}$ differs from that of the catalysts.

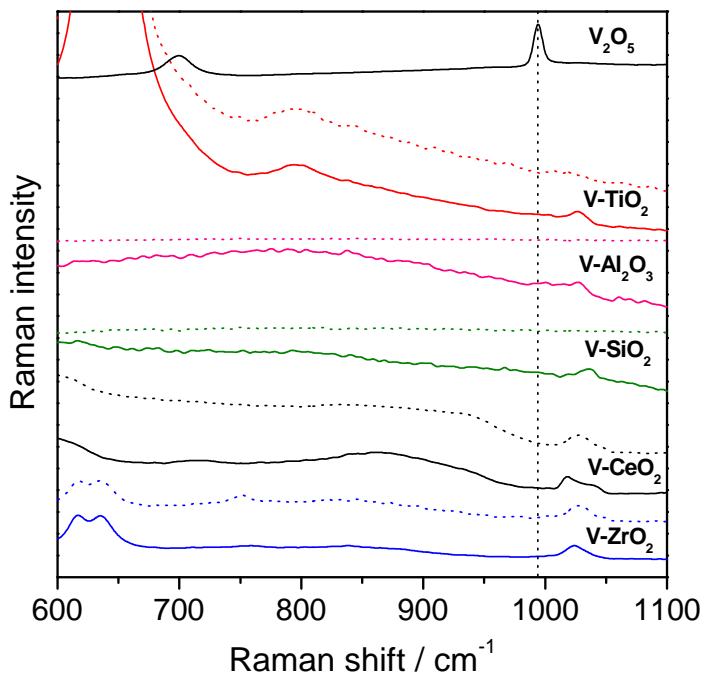

Fig. 4: Raman spectra of dehydrated $\mathrm{V}-\mathrm{Al}_{2} \mathrm{O}_{3}, \mathrm{~V}-\mathrm{TiO}_{2}, \mathrm{~V}-\mathrm{CeO}_{2}$, $\mathrm{V}-\mathrm{SiO}_{2}, \mathrm{~V}-\mathrm{ZrO}_{2}$ before (solid lines) and after reaction (dashed lines). $\mathrm{V}_{2} \mathrm{O}_{5}$ depicted as a reference. Spectra are offset for clarity.

Graph. 4 depicts Raman spectra of dehydrated V$\mathrm{Al}_{2} \mathrm{O}_{3}, \mathrm{~V}-\mathrm{TiO}_{2}, \mathrm{~V}-\mathrm{CeO}_{2}, \mathrm{~V}-\mathrm{SiO}_{2}, \mathrm{~V}-\mathrm{ZrO}_{2}$ before and after exposure to the reaction mixture and also contains a spectrum of $\mathrm{V}_{2} \mathrm{O}_{5}$ as reference. Before the reaction all catalysts exhibit vanadia-related Raman bands within 1015-1045 cm ${ }^{1}$. For some of the after-reaction samples these bands peaks are weaker or have completely disappeared.

Graph. 5 gives a detailed view of the range of the vanadyl stretch vibrations and reveals that the position as well as the shape of the Raman bands is quite different for the different support materials

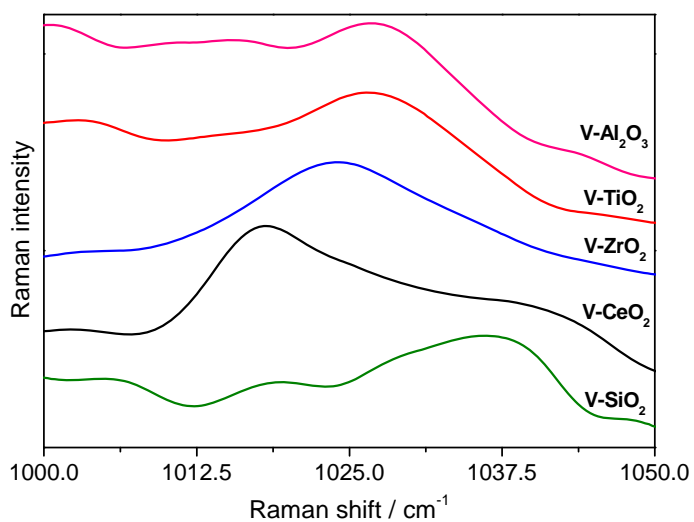

Fig. 5: Raman spectra of dehydrated $\mathrm{V}-\mathrm{Al}_{2} \mathrm{O}_{3}, \mathrm{~V}-\mathrm{TiO}_{2}, \mathrm{~V}-\mathrm{CeO}_{2}$, $\mathrm{V}-\mathrm{SiO}_{2}, \mathrm{~V}-\mathrm{ZrO}_{2}$ before reaction. Spectra are offset for clarity. 


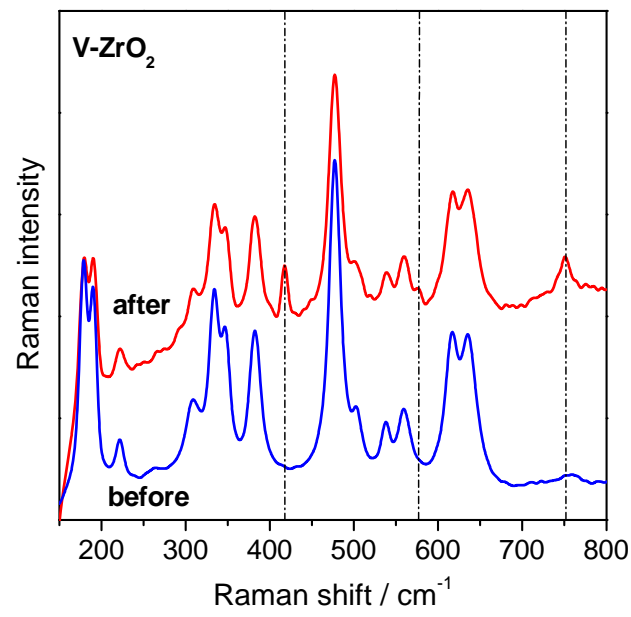

Fig. 7: Raman spectrum of $\mathrm{V}-\mathrm{ZrO}_{2}$ before and after reaction

For $\mathrm{V}-\mathrm{ZrO}_{2}$ the catalyst showed major Raman bands at $179,190,334,347,382,477,617$ and $635 \mathrm{~cm}^{-1}$ before the reaction, which are characteristic of monoclinic zirconia [29]. For the after-reaction sample additional small bands at 417, 576 and $750 \mathrm{~cm}^{-1}$ were observed (Graph. 6).

To ensure isothermal conditions, the reactor temperature profile of propene combustion on a zirconia supported vanadia catalyst was measured (Graph. 7) as this reaction represents the most exothermic partial reaction of the ODP reaction network on the most active catalyst. It was used to acquire the worst case reactor temperature profile. This ensures less pronounced profiles for all other reactions.

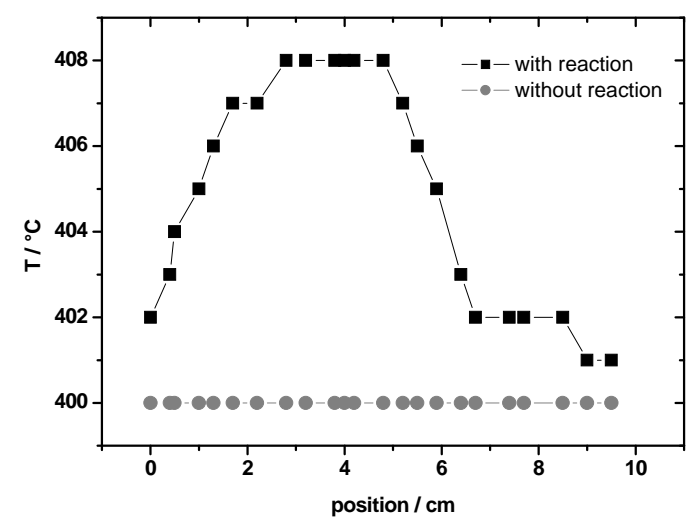

Fig. 6: Temperature profiles within the catalyst bed with and without reaction for the propene combustion on $\mathrm{V}-\mathrm{ZrO}_{2}$ at $400{ }^{\circ} \mathrm{C}$. With reaction: Composition: $\mathrm{C}_{3} \mathrm{H}_{6} / \mathrm{O}_{2} / \mathrm{N}_{2}=29.1 / 14.5 / 56.4$; gas

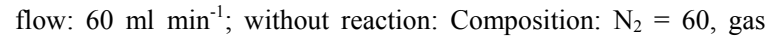
flow: $60 \mathrm{ml} \mathrm{min}^{-1}$, respectively.

In order to exclude mass transfer limitations, selectivity-conversion trajectories for the most active catalyst $\mathrm{V}$ $\mathrm{ZrO}_{2}$ were recorded for different particle sizes. As described previously [23], similar trajectories depicted in Graph. 8, reveal, that the effect of mass transfer limitations at $400{ }^{\circ} \mathrm{C}$ is negligible.

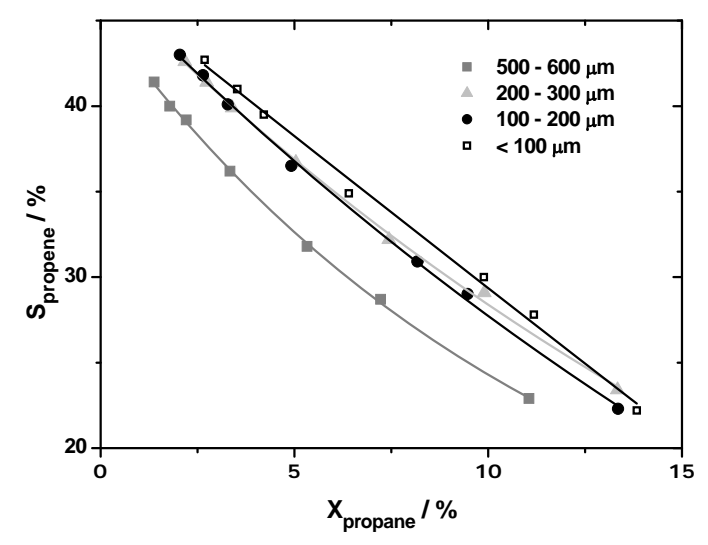

Fig. 8: Selectrivity-Conversion trajectories for $\mathrm{V}-\mathrm{ZrO}_{2}$ at $400{ }^{\circ} \mathrm{C}$ for different particle sizes. $\mathrm{C}_{3} \mathrm{H}_{8} / \mathrm{O}_{2} / \mathrm{N}_{2}=29.1 / 14.5 / 56.4$ at a total gas flow of $60 \mathrm{ml} \mathrm{min}^{-1}$. Lines are to guide the eye.

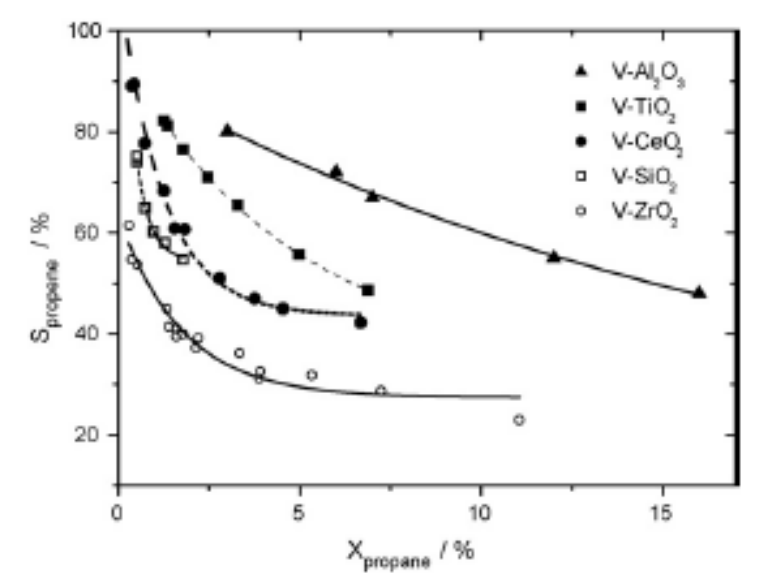

Fig. 9: Selectivity-conversion trajectories for $\mathrm{V}-\mathrm{Al}_{2} \mathrm{O}_{3}, \mathrm{~V}-\mathrm{TiO}_{2}, \mathrm{~V}$ $\mathrm{CeO}_{2}, \mathrm{~V}-\mathrm{SiO}_{2}$ and $\mathrm{V}-\mathrm{ZrO}_{2}$ at $400{ }^{\circ} \mathrm{C} . \mathrm{C}_{3} \mathrm{H}_{8} / \mathrm{O}_{2} / \mathrm{N}_{2}=29.1 / 14.5 / 56.4$ at a total gas flow of $60 \mathrm{ml} \mathrm{min}^{-1}$. Lines are to guide the eye.

Graph. 9 shows the selectivity conversion trajectories of the differently supported catalysts at $400{ }^{\circ} \mathrm{C}$. It is evident that there are large differences in selectivity towards propene in the studied conversion range. The order of selectivities at isoconversion at $400{ }^{\circ} \mathrm{C}$ is $\mathrm{V}-\mathrm{Al}_{2} \mathrm{O}_{3}>\mathrm{V}-\mathrm{TiO}_{2}>$ $\mathrm{V}-\mathrm{CeO}_{2}>\mathrm{V}-\mathrm{SiO}_{2}>\mathrm{V}-\mathrm{ZrO}_{2}$. For all catalysts except V$\mathrm{ZrO}_{2}$, propene selectivities seem to approach selectivites near $100 \%$ at zero conversion.

For all catalysts selectivities increase with temperature as depicted in Graph. 10. However, zero conversion intersections are independent of temperature and approach $100 \%$ selectivity values at low conversions.

As the next step, activation energies of the partial reactions were investigated by measuring initial reaction rates of ODP and propene combustion separately as function of temperature. Activation energies were then derived from Arrhenius-plots. The results are summarized in Tab. 2. 

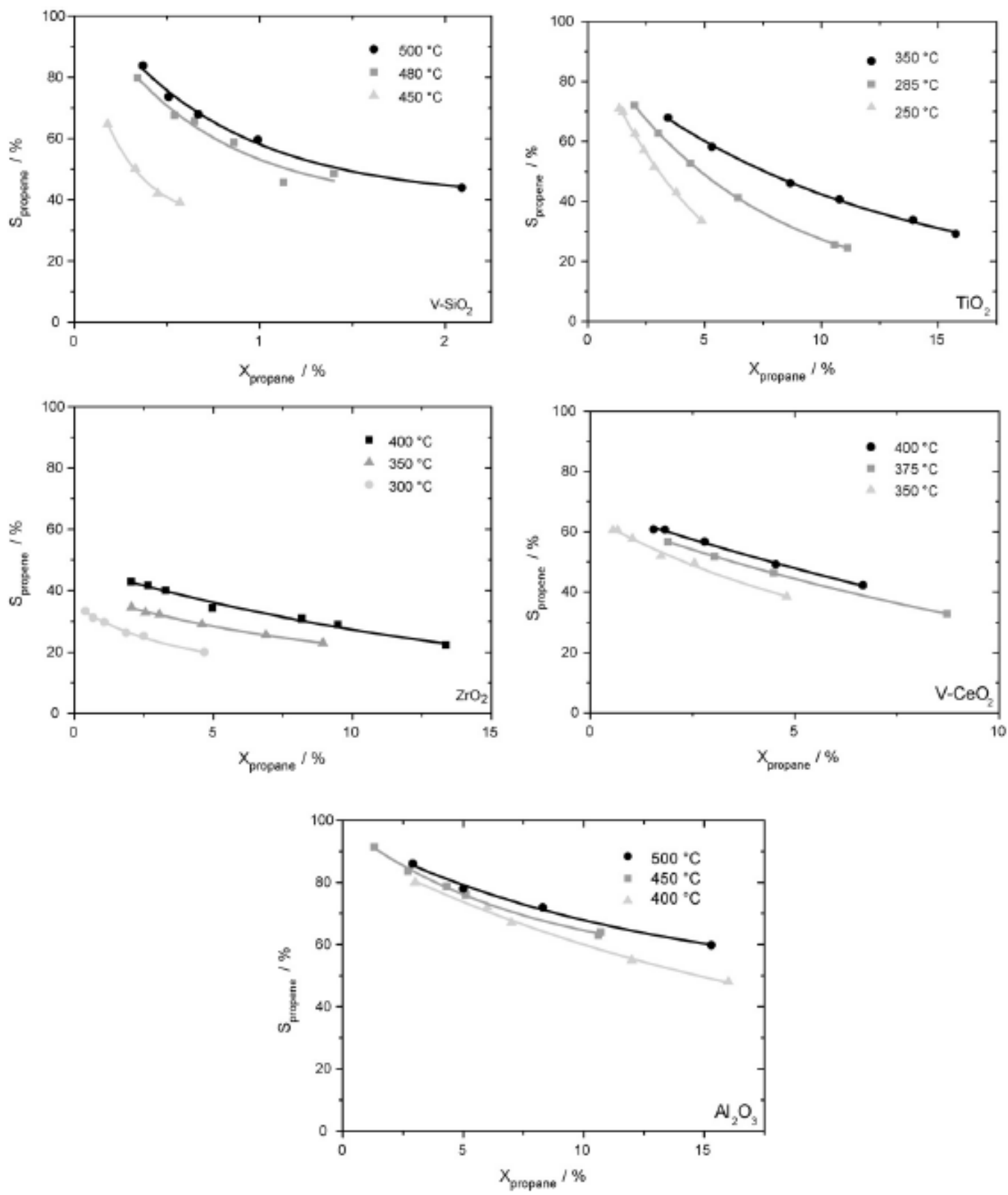

Fig. 10: Selectivity-Conversion trajectories at different temperatures for $\mathrm{V}-\mathrm{Al}_{2} \mathrm{O}_{3}, \mathrm{~V}-\mathrm{TiO}_{2}, \mathrm{~V}-\mathrm{CeO}_{2}, \mathrm{~V}-\mathrm{SiO}_{2}$ and $\mathrm{V}-\mathrm{ZrO}_{2} . \mathrm{C}_{3} \mathrm{H}_{8} / \mathrm{O}_{2} / \mathrm{N}_{2}=$ 29.1/14.5/56.4 at a total gas flow of $60 \mathrm{ml} \mathrm{min}^{-1}$

Table 2: Activation energies and TOF $\left(400^{\circ} \mathrm{C}\right)$ of ODP and propene combustion on differently supported vanadia catalysts. $\mathrm{C}_{3} \mathrm{H}_{\mathrm{x}} / \mathrm{O}_{2} / \mathrm{N}_{2}=29.1 / 14.5 / 56.4$ at a total gas flow of $60 \mathrm{ml} \mathrm{\textrm {min } ^ { - 1 }}$

\begin{tabular}{|c|c|c|c|c|}
\hline catalyst & $\begin{array}{l}E_{\mathrm{a}, \text { propane }} \\
\mathrm{kJ} \mathrm{mol}^{-1}\end{array}$ & $\begin{array}{l}\mathrm{E}_{\mathrm{a} \text {,propene }} \\
\mathrm{kJ} \mathrm{mol}^{-1}\end{array}$ & $\begin{array}{l}\text { TOF } \\
10^{-2} \mathrm{~s}^{-1} \\
\end{array}$ & $\begin{array}{l}\text { TOF } \\
10^{-2} \mathrm{~s}^{-1} \\
\end{array}$ \\
\hline $\mathrm{V}-\mathrm{TiO}_{2}$ & $56 \pm 5$ & $147 \pm 7$ & $5.8 \pm 0.2$ & $47 \pm 0.2$ \\
\hline $\mathrm{V}-\mathrm{CeO}_{2}$ & $68 \pm 6$ & $101 \pm 6$ & $3.4 \pm 0.2$ & $14 \pm 0.2$ \\
\hline $\mathrm{V}-\mathrm{ZrO}_{2}$ & $78 \pm 6$ & $100 \pm 6$ & $5.6 \pm 0.3$ & $5.7 \pm 0.3$ \\
\hline $\mathrm{V}-\mathrm{Al}_{2} \mathrm{O}_{3}$ & $113 \pm 6$ & $87 \pm 5$ & $0.68 \pm 0.4$ & $0.9 \pm 0.2$ \\
\hline $\mathrm{V}-\mathrm{SiO}_{2}$ & $146 \pm 6$ & $95 \pm 5$ & $0.13 \pm 0.1$ & $0.7 \pm 0.1$ \\
\hline
\end{tabular}

Generally, if different support materials have been compared in the literature with respect to their influence on ODP, contributions of the bare support material were not considered. Graph. 11 shows the propane and propene conversion on the bare supports used in this study in comparison to the corresponding vanadia loaded materials.

It can be seen that the contribution of the support material can be neglected for most of the catalyst/support combinations. An exception is $\mathrm{CeO}_{2}$, which reveals a high activity. Most surprising pure $\mathrm{CeO}_{2}$ exhibits even a higher activity than $\mathrm{V}-\mathrm{CeO}_{2}$. 

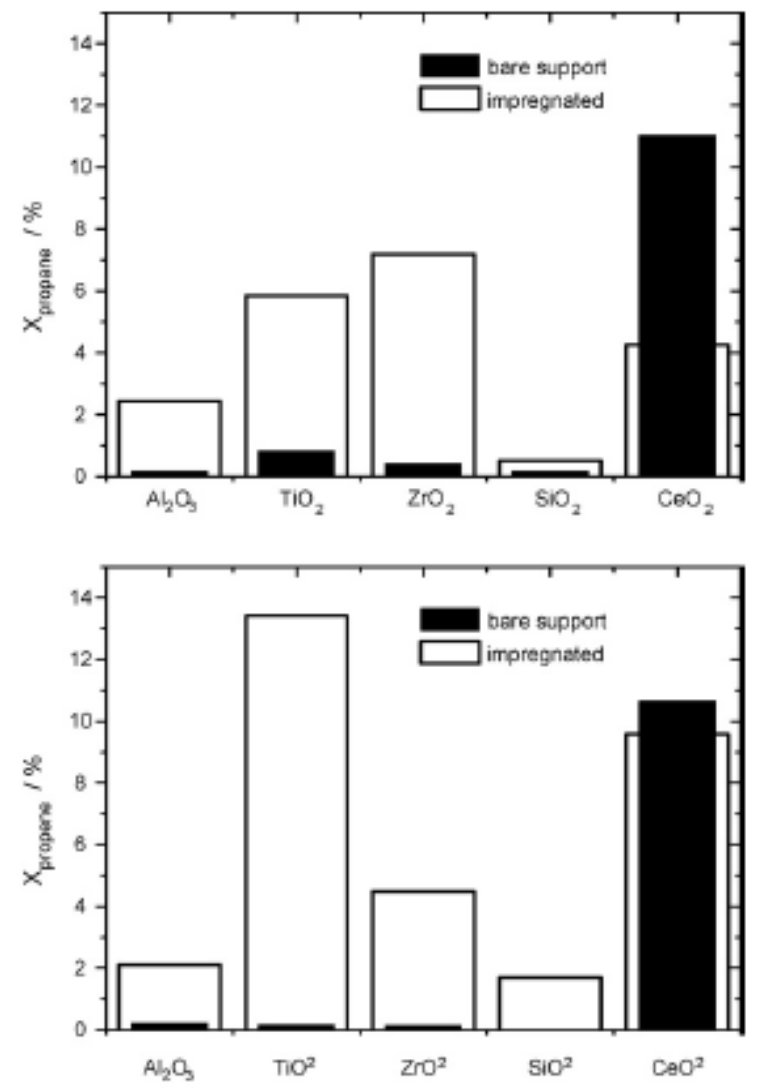

Fig. 11: Propane (top) and propene (bottom) conversions at $400^{\circ} \mathrm{C}$ and $350{ }^{\circ} \mathrm{C}$, respectively, over $\mathrm{V}-\mathrm{Al}_{2} \mathrm{O}_{3}, \mathrm{~V}-\mathrm{TiO}_{2}, \mathrm{~V}-\mathrm{CeO}_{2}, \mathrm{~V}-\mathrm{SiO}_{2}$, $\mathrm{V}-\mathrm{ZrO}_{2}$ (open) and $\mathrm{Al}_{2} \mathrm{O}_{3}, \mathrm{TiO}_{2}, \mathrm{CeO}_{2}, \mathrm{SiO}_{2}, \mathrm{ZrO}_{2}$ (filled), respectively. $\mathrm{C}_{3} \mathrm{H}_{\mathrm{x}} / \mathrm{O}_{2} / \mathrm{N}_{2}=29.1 / 14.5 / 56.4$ at a total gas flow of $60 \mathrm{ml}$ $\min ^{-1}$

Since $\mathrm{CeO}_{2}$ is an oxidation catalyst itself [30], this could be explained by surface vanadium species affecting the $\mathrm{CeO}_{2}$ active surface sites. In this case propane would react on ceria sites on $\mathrm{CeO}_{2}$ as well as on $\mathrm{V}-\mathrm{CeO}_{2}$ and is therefore not comparable to the other support materials used for our ODP study. As bare support and catalyst exhibit about the same surface area the higher conversion of the support cannot be associated to a loss of surface area during the preparation (calcination) of the catalyst. If propane would react only at a vanadia active site the lower conversion on $\mathrm{V}-\mathrm{CeO}_{2}$ compared to the bare support could not be explained. However, the reason for this behavior might be that there is still uncovered support material expected to be accessible for the reactants.

\section{Discussion}

\subsection{Catalyst Characterization}

Previous studies have shown a strong correlation of the catalytic performance with the surface concentration of vanadia species $[31,5,12]$. Low surface densities $(<2 \mathrm{~V}$ $\mathrm{nm}^{-2}$ ) were determined by ICP for all catalysts in this study, in case of the $\mathrm{SiO}_{2}$ support material being only $0.3 \mathrm{~V} \mathrm{~nm}^{-2}$ (Tab. 1). This might indicate a lower density of docking sites for vanadia species on $\mathrm{SiO}_{2}$. A study by Weckhuysen et al. [20], which shows that the maximum surface vanadium loading without generation of $\mathrm{V}_{2} \mathrm{O}_{5}$ is especially low for $\mathrm{SiO}_{2}\left(1-2 \mathrm{~V} \mathrm{~nm}^{-2}\right)$ compared to other support materials (7-8 $\left.\mathrm{V} \mathrm{nm}^{-2}\right)$, confirms this assumption. Very similar specific surface areas for the support materials and catalysts were observed by BET measurements, which indicate that clogging of pores by vanadium surface species is negligible.

Our TPR experiments show only one distinct reduction peak below $630{ }^{\circ} \mathrm{C}$. This indicates that the reducibility of all catalytic active sites is similar and the presence of $\mathrm{V}_{2} \mathrm{O}_{5}$ may be excluded which is confirmed by [23]. The additional shoulder, which is found in the case of $\mathrm{V}-\mathrm{CeO}_{2}$ may be assigned to $\mathrm{CeO}_{2}$ surface species [32]. XRD patterns also do not show any $\mathrm{V}_{2} \mathrm{O}_{5}$-related peaks. However, due to the limited sensitivity of XRD for the detection of $\mathrm{V}_{2} \mathrm{O}_{5}$ micro crystals, visible Raman spectra were additionally recorded.

The Raman spectra of dehydrated $\mathrm{V}-\mathrm{Al}_{2} \mathrm{O}_{3}, \mathrm{~V}-\mathrm{TiO}_{2}$, $\mathrm{V}-\mathrm{CeO}_{2}, \mathrm{~V}-\mathrm{SiO}_{2}$ and $\mathrm{V}-\mathrm{ZrO}_{2}$ show bands within 1015$1045 \mathrm{~cm}^{-1}$, which are assigned to the vanadyl stretch vibrations of dispersed vanadium oxide in agreement with literature data [20]. The small peak at $994 \mathrm{~cm}^{-1}$, observed for $\mathrm{V}$ $\mathrm{Al}_{2} \mathrm{O}_{3}$, indicates the presence of small amounts of crystalline $\mathrm{V}_{2} \mathrm{O}_{5}$ species (see Graph. 3). Please note, that the amount of $\mathrm{V}_{2} \mathrm{O}_{5}$ detected is significantly lower than the fraction of peak areas, because the Raman cross section of the vanadyl band of these species is at least 5 times larger than that of the dispersed vanadia species [33].

The reason for the disappearance of some Raman bands after the reaction may be that the deposited coke was not completely combusted after the special treatment prior to Raman experiments. The residual carbon then absorbs most of the Raman light. In addition, carbon may cover part or even all of the surface vanadium oxide species, which may lead to a further decrease in the Raman intensity. The origin of the new Raman bands for $\mathrm{V}-\mathrm{ZrO}_{2}$ arising after reaction is currently under investigation. However, it should be pointed out that they neither match the known Raman band positions of tetragonal and cubic zirconia phases [29] nor those of $\mathrm{ZrV}_{2} \mathrm{O}_{7}$ [34].

Summarizing, the results discussed above demonstrate that at most small amounts of crystalline $\mathrm{V}_{2} \mathrm{O}_{5}$ are present at the support and a highly dispersed system is available. This is an important observation, because bulk vanadia leads to a decrease in specific activity as buried vanadium atoms are not accessible for catalysis, while they would still be counted for the calculation of TOF. On the other hand, studies by Kondratenko et al. [5, 6] showed that crystalline particles also decrease the selectivity towards propene. Therefore, if different amounts of crystalline $\mathrm{V}_{2} \mathrm{O}_{5}$ are deposited on a support surface during catalyst preparation, the catalytic performances of the different catalysts would not be directly comparable. Additionally it was 
shown that the $\mathrm{V}-\mathrm{ZrO}_{2}$ catalyst was not stable under reaction conditions, which has not been pointed out so far. Most important, the difference in position and shape of the vanadyl-related Raman bands of the prepared catalysts clearly indicate structural variations of the surface vanadium oxide species on the different support materials. This observation is at variance with the theories about the influence of support material that have been stated in literature so far. In these models identical vanadyl species were supposed to exist, independent of the respective support material. Studies to identify the different species observed are in progress.

\subsection{Influence of support material on catalytic performance}

One of the most important observations of this study is the strong influence of the support material on the catalytic performance in ODP. In case of $\mathrm{SiO}_{2}$ it was furthermore verified, that no change in selectivity-conversion dependence could be detected when modifying the support structure [35]. Apparently structural changes alone do not affect the catalytic performance of ODP. One would be tempted to relate this negative result to the observation of Iglesia et al. [36] and Hess et al. [37], suggesting that water hydrolyses the V-O-support bond on $\mathrm{SiO}_{2}$ and forming $\mathrm{V}_{2} \mathrm{O}_{5} \cdot \mathrm{H}_{2} \mathrm{O}$ gels, which are disconnected from the support material. However, under reaction conditions this cannot occur because of high temperatures and resulting low $\mathrm{H}_{2} \mathrm{O}$ surface coverage.

The low loadings $\left(<2 \mathrm{~V} \mathrm{~nm}^{-2}\right)$ for this study were chosen to detect support effects, which are hidden with higher vanadia loadings, as was shown by Khodakov et al. [12]. They concluded that the initial influence of the support material on the distribution of monomeric and oligomeric vanadia species decreases with the formation of polymeric vanadia species, because at higher loadings differences in cluster formation can no longer influence the result. This argument is supported by Shee et al. [38]. They recently found the same selectivity-conversion behavior for a titania and alumina supported catalyst at higher loadings $\left(5 \mathrm{~V} \mathrm{~nm}^{-2}\right)$, excluding the influence of $\mathrm{V}_{2} \mathrm{O}_{5}$ surface species and mass transfer limitations.

Concerning the activity of supported vanadia catalysts which is determined by the active site taking part in the rate determining step, two models can be found in the literature:

Wachs et al. [1] found a substantial impact of EN of the support on the catalytic activity of the methanol oxidation, expressed as an exponential dependence of TOF on EN. They concluded that the V-O-support bond is the crucial reactive site. For ODP, however, theoretical calculations predict the $\mathrm{V}=\mathrm{O}$ to take part in the rate determining step. On the basis of DFT calculations, Rozanska et al. [26] find the vanadyl oxygen to be responsible for the selective dehydrogenation of propane over silica supported vanadia catalysts. Although similar calculations have not been done so far for other support materials, a study of Bell et al. [27] for unsupported $\mathrm{V}_{2} \mathrm{O}_{5}$ also assign the $\mathrm{V}=\mathrm{O}$ as the crucial active site for the first $\mathrm{C}-\mathrm{H}$ bond abstraction as the rate determining, though the second hydrogen abstraction may involve a V-O-V bond. In order to obtain additional information to enable discrimination between these models, we determined the dependence of ODP TOFs and activation energies on the EN of the cation of the respective support material.
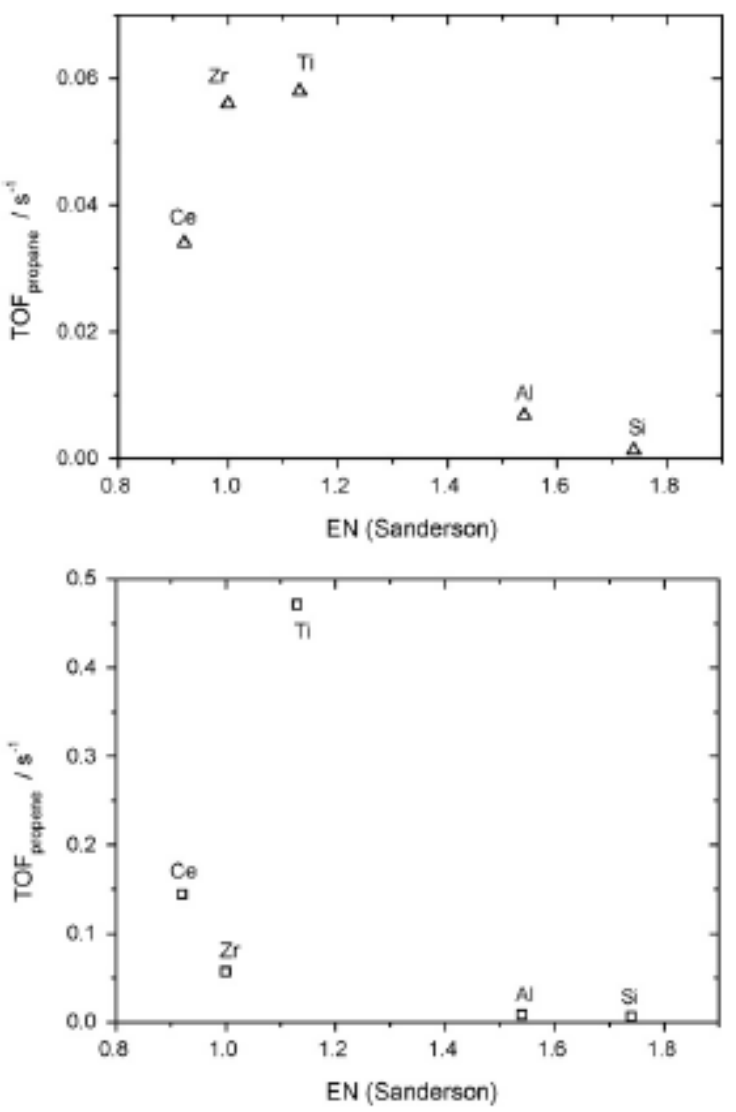

Fig. 12: Turn-over frequencies of ODP (top) and propene (bottom) combustion on $\mathrm{V}-\mathrm{Al}_{2} \mathrm{O}_{3}, \mathrm{~V}-\mathrm{TiO}_{2}, \mathrm{~V}-\mathrm{CeO}_{2}, \mathrm{~V}-\mathrm{SiO}_{2}$ and $\mathrm{V}-\mathrm{ZrO}_{2}$ plotted against electronegativity of support material cation.

From Graph. 12 it can be seen that the TOF values vary by one order of magnitude, which demonstrates the strong influence of the support material on ODP. The TOF values of propene combustion are about one order of magnitude higher than those for ODP as it was expected due to the low selectivity caused by a fast consecutive combustion of propene in ODP. However, a general problem of a discussion of activities on the basis of TOF values is given by the fact that for TOF calculations it is assumed that all surface vanadia species contribute equally to the catalytic reaction. This would only be the case if all catalytically active species were structurally identical. Furthermore, vanadium atoms, enclosed in $\mathrm{V}_{2} \mathrm{O}_{5}$ particles contribute to the calculated TOF values as well and therefore could prevent correct interpretation. As alternative, we discuss the 
dependence of activation energies on EN, avoiding this problem.

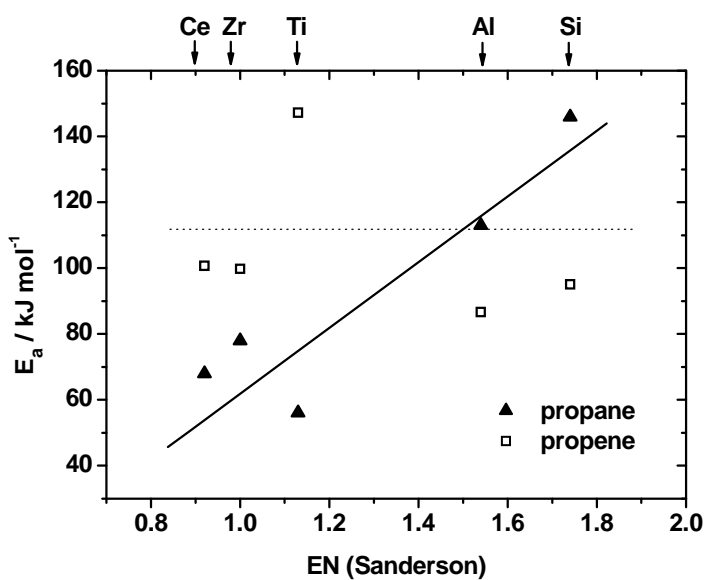

Fig. 13: Activation energies of ODP and propene combustion on $\mathrm{V}-\mathrm{Al}_{2} \mathrm{O}_{3}, \mathrm{~V}-\mathrm{TiO}_{2}, \mathrm{~V}-\mathrm{CeO}_{2}, \mathrm{~V}-\mathrm{SiO}_{2}$, and $\mathrm{V}-\mathrm{ZrO}_{2}$ plotted against electronegativity of the support material cation. $\mathrm{C}_{3} \mathrm{H}_{8} / \mathrm{O}_{2} / \mathrm{N}_{2}=$ 29.1/14.5/56.4 at a total gas flow of $60 \mathrm{ml} \mathrm{min}^{-1}$

In Graph.13 activation energies for ODP, which were determined in our study, were plotted against EN values of the cation of the support material. They clearly increase with EN, whereas activation energies of the consecutive propene combustion are practically independent of EN $\left(100 \mathrm{~kJ} \mathrm{~mol}^{-1}\right)$ except for ${\mathrm{V}-\mathrm{TiO}_{2}}_{2}$. The difference between activation energies of propane dehydrogenation and propene combustion is quite large in the case of $\mathrm{V}-\mathrm{TiO}_{2}$. The dependence of activation energies on EN for the ODH step indicates a strong correlation of the catalytic reaction with physical properties of the support materials used for catalyst preparation. However, as well as TOFs, the activities for the ODH reaction do not seem to depend on the electronegativity of the support cation in a simple way.

The results obtained here lead to the conclusion that the influence of support materials on ODP is of a more complex nature, than was indicated by the interpretation of methanol oxidation. However, comparing the measured activation energy of ODP for $\mathrm{V}-\mathrm{SiO}_{2}\left(\sim 150 \mathrm{~kJ} \mathrm{~mol}^{-1}\right)$ one finds a good correlation with the values calculated by DFT calculation for the monomeric $\mathrm{V}=\mathrm{O}$ bond be the crucial active site in the rate determining step $\left(\sim 140 \mathrm{~kJ} \mathrm{~mol}^{-1}\right)$. For $\mathrm{V}-\mathrm{O}$-support bonds being the active site, the calculations revealed much higher activation energies $\left(\sim 200 \mathrm{~kJ} \mathrm{~mol}^{-1}\right)$ [26]. For an unsupported $\mathrm{V}_{2} \mathrm{O}_{5}$ cluster a value of about 160 $\mathrm{kJ} \mathrm{mol}^{-1}$ was calculated [27].

The selectivity of ODP may be influenced by one or several of the following three attributes: (i) Different oxygen-vanadium bonds, e.g. the relative amount of support-O$\mathrm{V}, \mathrm{V}-\mathrm{O}-\mathrm{V}$ or $\mathrm{V}=\mathrm{O}$ groups, (ii) the surface acidity of the respective support material and (iii) differently structured surface vanadium species. These catalyst properties and their possible influence on the product selectivities will be discussed in the following.

In many previous studies, especially if low loaded catalysts are investigated, monovanadate species are assumed to be the predominant active sites and therefore assigned to determine the selectivity of ODP $[39,40]$. In a new study of Bronkema et al. [41] using EXAFS, it was shown that only monovandate species to be existant on a SBA15 supported catalyst.

Recent studies of Klose et al., however, suggested a new structural model for vanadium surface species on alumina supported vanadium catalysts [42]. In their work a trimeric surface species, containing $\mathrm{V}^{5+}$ and $\mathrm{V}^{4+}$, is proposed under moderate oxidizing conditions even at vanadium loadings lower than $2 \mathrm{~V} \mathrm{~nm}^{-2}$. These species would exhibit support-O-V, $\mathrm{V}=\mathrm{O}$ as well as $\mathrm{V}-\mathrm{O}-\mathrm{V}$ bonds. Due to the known influence of support material of vanadia catalysts on ODP, they assumed the support-O-V bond to be the main active site. Furthermore, Hess et al. observed associated vanadia species on SBA15 supported catalysts at very low loadings $\left(0.7 \mathrm{~V} \mathrm{~nm}^{-2}\right)$ by probing with $\mathrm{NO}$ and $\mathrm{CO}$ molecules [43]. The different results discussed above show, that either support- $\mathrm{O}-\mathrm{V}$ and $\mathrm{V}=\mathrm{O}$ bonds with or without additionally available $\mathrm{V}-\mathrm{O}-\mathrm{V}$ bonds could influence the product selectivities in the case of low loaded catalysts.

An additional effect, which is expected to influence the reaction rate and selectivity to propene is the surface acidity. The attempt to relate surface acid-base properties of the support to activity and selectivity of ODP has already been a subject of previous investigations [44, 45]. However, these results have to be considered with care because of missing analytical characterization and the neglect of mass and heat transfer effects. Furthermore, in both studies, TPR experiments reveal the presence of different reducible vanadium surface species as well as surface $\mathrm{V}_{2} \mathrm{O}_{5}$ species, which makes a comparison of the catalysts difficult.

In order to rationalize the observed relative selectivities, we first exclude the $\mathrm{V}-\mathrm{CeO}_{2}$ and $\mathrm{V}-\mathrm{SiO}_{2}$ data. $\mathrm{CeO}_{2}$ reveals a higher propane conversion on the bare support material than the corresponding catalyst, which indicates Cerium sites instead of Vanadium sites to be active. The documented differences in loading properties of $\mathrm{SiO}_{2}$ also suggest a generally different site structure. The apparent similarity of the Raman of the remaining group supports our choice to discuss the catalytic properties within this restricted set.

The $\mathrm{pH}$ at which the surface possesses zero surface charge shows the following trend:

$$
\mathrm{V}-\mathrm{ZrO}_{2}<\mathrm{V}-\mathrm{TiO}_{2}<\mathrm{V}-\mathrm{Al}_{2} \mathrm{O}_{3}
$$

This is the same trend as has been observed for the selectivities of these catalysts, even though it is not as pronounced. Thus, a consideration of surface acidity of the catalyst may connect propene selectivity to surface acidity of the support. (In this context we want to mention that the 
relative order of reducibilities determined by TPR predicts the observed trend of catalyst activities expressed in TOF). At Vanadium loadings below $2 \mathrm{~V} \mathrm{~nm}^{-2}$, Broensted acid sites can be excluded referring to [46] and [19]. In these studies the presence of surface acid sites for $\mathrm{V}-\mathrm{ZrO}{ }_{2}$ and $\mathrm{V}$ $\mathrm{Al}_{2} \mathrm{O}_{3}$ was investigated. At Vanadium surface densities $<2$ $\mathrm{V} \mathrm{nm}{ }^{-2}$ no Broensted sites were found and the number of Lewis acid sites was slightly decreased compared to the bulk support material.

It is noteworthy that high resolution Raman spectra give clear evidence for a certain heterogeneity of Vanadium sites under low loading conditions. This leads to spectral differences even for the restricted set of support materials. For this reason with the current experimental data it cannot be excluded that this distribution of local site structure could also be influencing the relative order of activities and selectivities.

\subsection{Reaction network}

Additional studies on the selectivities of ODP towards propene make it possible to decide whether parts of the reaction network may be neglected leading to a significant simplification of the kinetic simulations. This information can be derived from the selectivity towards propene at low propane conversions. Except for $\mathrm{ZrO}_{2}$, the ODP selectivity-conversion trajectories for the different catalysts approach selectivities of about $100 \%$ at low conversions. If there was significant parallel combustion of propane to carbon oxides, selectivities should be lower also at low conversions. This leads to the hypothesis that the consecutive reaction of propane is the main factor that determines selectivity. For $\mathrm{V}-\mathrm{Al}_{2} \mathrm{O}_{3}$ and $\mathrm{V}-\mathrm{TiO}_{2}$ this is confirmed by studies described in the literature. For alumina supported catalysts [47] the selectivity also approached $100 \%$ selectivity at low conversions. In a kinetic study Viparelli et al. [48] considered the rate constant $\mathrm{k}_{2}$, which describes the rate of the parallel propane combustion (scheme 1) to be zero for a titania supported vanadia catalyst. In contrast, zirconia supported catalysts show poor selectivities even at very low conversions. This could be explained by parallel combustion of propane. A different explanation would be that propene formed at low conversions may not desorb from the active site or adjacent Lewis acid sites due to a strong adsorption resulting in a deep oxidation to $\mathrm{CO}_{\mathrm{x}}$. According to results of isotopic tracer experiments performed by Bell et al. [7], a parallel combustion of propane seems to be more likely. This study reports $\mathrm{CO}_{2}$ being formed via direct combustion of propane. However, it has to be mentioned that the fraction of parallel combustion is low. It may also be possible that both, deep oxidation of propene even at low conversions and parallel combustion may be part of ODP over $\mathrm{V}-\mathrm{ZrO}_{2}$.

The increase in selectivity with increasing temperature indicates a stronger reaction rate increase of propane dehydrogenation than consecutive propene combustion and other side step reactions, respectively. Based on these results one would expect the highest activation energy within the reaction network for the ODH step. For alumina supported catalysts the selectivity increase with temperature was confirmed by Bell et al. [39]. In this kinetic study, the ratio of $\mathrm{k}_{3} / \mathrm{k}_{1}$ was found to decrease with increasing temperature corresponding to a higher activation energy for oxidative dehydrogenation of propane than for the consecutive combustion. However, the separate investigations of ODP and the combustion of propene with different supported catalysts do not follow the expectation mentioned above. $\mathrm{V}-\mathrm{CeO}_{2}, \mathrm{~V}-\mathrm{ZrO}_{2}$ and $\mathrm{V}-\mathrm{TiO}_{2}$ activation energies for ODP are lower than those for the consecutive propene combustion (Table 2). This indicates that the two reactions may not be described as separated individual reactions at least in case of $\mathrm{V}-\mathrm{CeO}_{2}, \mathrm{~V}-\mathrm{ZrO}_{2}$ and $\mathrm{V}-\mathrm{TiO}_{2}$.

Usually subdivision is an accepted tool for kinetic investigations [49]. For $\mathrm{V}-\mathrm{SiO}_{2}$ and $\mathrm{V}-\mathrm{Al}_{2} \mathrm{O}_{3}$ the correspondence of the selectivity-temperature dependence and activation energies may allow the two reactions to be investigated separately as done in [23]. But the agreement of the results may be a coincidence. This has to be taken into account for future kinetic investigations.

A reason for this may be the different average oxidation state of the catalyst during the separately studied oxidation of propane and propene, respectively. This is due to propene consuming more lattice oxygen during its combustion than propane during its dehydrogenation. Furthermore, the combustion of propene is faster than the ODP. Since the rate of propene combustion is also proportional to the number of active lattice oxygen site, it gets slow as its concentration decreases, and the reoxidation of the catalyst becomes the rate determining step.

This consideration is supported by mechanistic studies [50, 51, 14], in which a Mars-van Krevelen (MvK) approach is used to describe the kinetics of ODP:

$$
\begin{aligned}
& r_{1}=k_{1} p_{C 3 H 8}(1-\beta) \\
& r_{2}=k_{2} p_{C 3 H 6}(1-\beta) \\
& r_{3}=k_{3} p_{O 2} \beta
\end{aligned}
$$

with $k_{i}$ the respective rate constant and $p_{i}$ the respective partial pressure. The degree of reduction $\beta$ is here defined by the ratio of catalyst reducing reactions and the sum of reducing and reoxidizing reactions, given by the steady-state mass balance of active sites:

$$
\beta=\frac{0.5 k_{1} P_{C 3 H 8}+3 k_{2} P_{C 3 H 6}}{0.5 k_{1} P_{C 3 H 8}+3 k_{2} P_{C 3 H 6}+k_{3} P_{O 2}}
$$

If catalyst reduction is fast, which is the case in propene combustion, the degree of reduction $\beta$ is high. In a 
steady state for which rates of reduction and reoxidation are balanced we have:

$r_{2}=r_{3}$

so $k_{3}$ would be small compared to $k_{2}$, which leads to the fact, that the reoxidation of the catalyst is the ratedetermining step. Therefore the activation energies for propene combustion measured in this study reveal only apparent activation energies for this reaction, which corresponds to the activation energy of the reoxidation step.

It should also be noted that recent considerations [52] concerning the application of MvK-approaches for kinetic investigations have to be used carefully in terms of a physical interpretation of experimental results. However, the application of a MvK model for the above discussion may be an appropriate tool to describe the issue of ODP kinetics in a descriptive way.

\section{Conclusion}

1. Different support materials show a strong influence towards activity and selectivity of equally prepared catalysts for ODP. The catalytic performance seems to depend on a complex interplay of vanadium surface species and bulk supporting material, which cannot easily be modelled by invoking the corresponding cation electronegativities. All catalysts expose differently structured and/or distributed vanadium surface sites (monomers / oligomers). Therefore a comparison has to be done carefully on the basis of further detailed investigations on the vanadia structure. We also find that $\mathrm{V}-\mathrm{ZrO}_{2}$ undergoes structural changes under reaction conditions.

2. For a future microkinetic evaluation of the investigated catalysts a simplified reaction network containing only consecutive propene combustion seems to be appropriate except for zirconia supported catalysts, and will simplify such investigations to a large extend.

3. ODP must not be investigated in terms of the particular partial reactions. That is, for multiple parameter determination, several experimental data sets have to be acquired. The separated investigation of catalyst reoxidation appears helpful and in addition extensive in situ characterisation and isotopic tracer experiments will be necessary to unravel possible microkinetic models.

4. To improve selectivity towards the desired product, high temperatures seem to be appropriate, independent of the nature of support material. Temperatures are limited by the fact that unselective gas phase reactions may occur above $550^{\circ} \mathrm{C}$.

\section{Acknowledgement}

This work was supported by the German Research Foundation (Deutsche Forschungsgemeinschaft, DFG) through the corporate research center "Structure, dynamics and reactivity of transition metal oxide aggregates" (Sonderforschungsbereich 546, http://www.chemie.huberlin.de/sfb546). The authors are furthermore grateful to Oliver Schwarz and Harald Link for experimental assistance. Christian Hess thanks the DFG for providing an Emmy Noether fellowship.

\section{References}

[1] I.E. Wachs, Catal. Today 100 (2005) 79.

[2] O.V.Buyevskaya, M. Baerns, Catal. Today 42 (1998) 315

[3] E.A. Mamedov, V. Cortés Corberan, Appl. Catal. A 127 (1995) 1

[4] T. Blasco, F. Trifiro, J. Catal. 169 (1997) 203

[5] E.V. Kondratenko, M. Cherian, J. Catal. 234 (2005) 131

[6] E.V. Kondratenko, O. Ovsister, Appl. Catal. A 319 (2007) 98

[7] K. Chen, A.T. Bell, E. Iglesia, J. Catal. 186 (1999) 325

[8] H. Wang, C. Tablet, T. Schiestel, J. Caro, Catal. Today 118 (2006) 98.

[9] D. Creaser, B. Andersson, R.R. Hudgins, Chem. Eng. Sci. 54 (1999) 4437.

[10] M. Cherian, G. Deo, Catal. Today 78 (2003) 397

[11] O.R. Evans, A.T. Bell, J. Catal. 226 (2004) 292

[12] A. Khodakov, A.T. Bell, E. Iglesia, J. Catal. 181 (1999) 205

[13] R. Grabowski, Appl. Catal. A 232 (2002) 277

[14] R. Grabowski, Appl. Catal. A 242 (2003) 297

[15] A. Bottino, G. Capanelli, Chem. Eng. J. 94 (2003) 11

[16] M.M. Barsan, F.C. Thyrion, Catal. Today 81 (2003) 159

[17] G. Martra, F. Arena, Catal. Today 63 (2000) 197

[18] V. Cortés Corberan, Catal. Today 99 (2005) 33

[19] M.V. Martinez-Huerta, I.E. Wachs, M.A. Banares, Catal. Today 118 (2006) 279

[20] B.M. Weckhuysen, D.E. Keller, Catal. Today 78 (2003) 25 and references therein

[21] Z. Wu, P.C. Stair, J. Phys. Chem. B 109 (2005) 2793

[22] A. Bottino, G. Capannelli, Chem. Eng. J. 94 (2003) 11

[23] B. Frank, A. Dinse, R. Schomaecker, Appl. Catal. A 323 (2007) 66

[24] E.V. Kondratenko, N. Steinfeldt, M. Baerns, Phys. Chem. Chem. Phys. 8 (2006) 1624

[25] D. Craeser, B. Andersson, R.R. Hudgins, Appl. Catal. A 187 (1999) 147

[26] X. Ronzanska, R. Fortrie, J. Sauer, J. Phys. Chem. B, accepted

[27] F. Gilardoni, A.T. Bell, J. Phys. Chem. B 104 (2000) 12250

[28] C. Hess, Surf. Sci. 600 (2006) 3695 
[29] D. Gazzoli, G. Mattei, M. Valigi, J. Raman Spectrosc. 38 (2007) 824]

[30] S. Zhao, P.J. Gorte, Appl. Catal. A 277 (2004) 129

[31] O. Schwarz, A. Dinse, B. Frank, R. Schomaecker, Catal. Commun. 9 (2008) 229

[32] Yao, H. C.; Yu Yao, Y. F. J. Catal. 86 (1984) 254

[33] C. Hess, G. Tzolova-Müller, R. Herbert, J. Phys. Chem. C 111 (2007) 9471

[34] M. Sanati, A. Andersson, B. Rebenstorf, Appl. Catal. A 106 (1993) 51

[35] O. Ovsister, M. Cherian, E. Kondratenko J. Phys. Chem. C 111 (2007) 8594

[36] S. Xie, E. Iglesia, A.T. Bell, Langmuir 16 (2000) 7162

[37] C. Hess, R. Schlögl, Chem. Phys. Let. 432 (2006) 139

[38] D. Shee, T.V. Malleswara, G. Deo Catalysis Today 118 (2006) 288

[39] A. Khodakov, E. Iglesia, A.T. Bell, J. Catal. 177 (1998) 343
[40] M.D. Argyle, K. Chen, A.T. Bell, E. Iglesia, J. Catal. 208 (2002) 139

[41] J. L. Bronkema, A.T. Bell, J. Phys. Chem 111 (2007) 420

[42] F. Klose, A. Seidel-Morgenstern, H. Weiss, J. Catal. 247 (2007) 176

[43] T. Venkov, C. Hess, F. Jentoft, Langmuir 23 (2007) 1768

[44] F. Arena, F. Frusteri, P. Parmaliana, Catal. Lett. 60 (1999) 59

[45] A.A. Lemonidou, L. Nalbandian, Catal. Today 61 (2000) 333

[46] K. Scheurell, E. Hoppe, E. Kemnitz, J. Mater. Chem. 14 (2004)

[47] E.V. Kondratenko, M. Baerns, Appl. Catal. A 222 (2001) 132

[48] P. Viparelli, P. Ciambelli, Appl. Catal. A 184 (1999) 291

[49] H.S. Fogler, Reaction Engineering, third ed., Prentice-Hall, New Jersey, (1999)

[50] K. Routray, G. Deo, Appl. Catal. A 265 (2004) 103

[51] K. Routray, G. Deo, AIChE 51 (2005) 1733

[52] M. Vannice Albert, Catal. Today 123 (2007) 18 